\title{
Simultaneous Prediction of Cryptosporidium parvum Oocyst Inactivation and Bromate Formation during Ozonation of Synthetic Waters
}

\author{
Jae-Hong Kim ${ }^{1}$, Urs von Gunten ${ }^{2}$, and Benito J. Mariñas ${ }^{3}$ \\ ${ }^{\mathbf{1}}$ School of Civil and Environmental Engineering, Georgia Institute of Technology, \\ Atlanta, GA 30332-0512 \\ ${ }^{2}$ Swiss Federal Institute for Environmental Science and Technology (EAWAG), \\ Ueberlandstrasse 133, CH-8600, Dübendorf, Switzerland \\ ${ }^{3}$ Department of Civil and Environmental Engineering, University of Illinois at Urbana- \\ Champaign, Urbana, IL 61801
}

\section{Supporting Information}

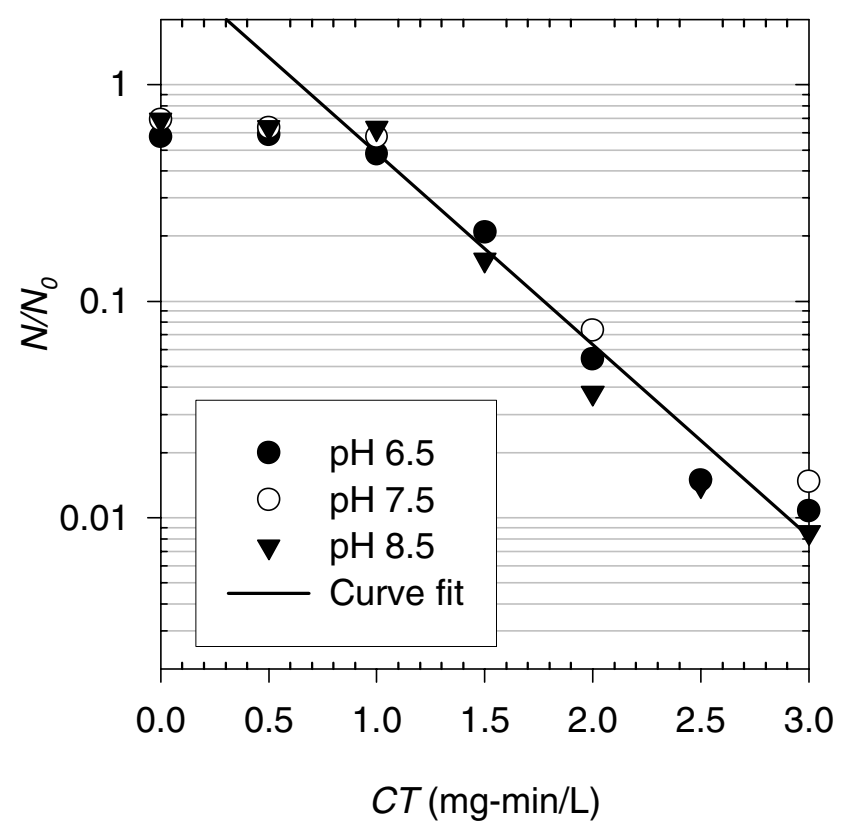

Figure S1. Inactivation kinetics of C. parvum oocysts from Lot B during semi-batch ozonation $\left(C_{T, \mathrm{PO} 4}=10 \mathrm{mM} ; \mathrm{T}=20^{\circ} \mathrm{C}\right)$. The lag-phase factor $N_{1} / N_{0}=3.72$ (dimensionless) and the pseudofirst order kinetic rate constant $k_{N}=2.04 \mathrm{~L} / \mathrm{mg}$-min were obtained from the intercept and the slope, respectively, of the line fitted to the post-lag phase data. The results were similar to those obtained with C. parvum oocysts from Lot A shown in Figure 9 of the main paper. 

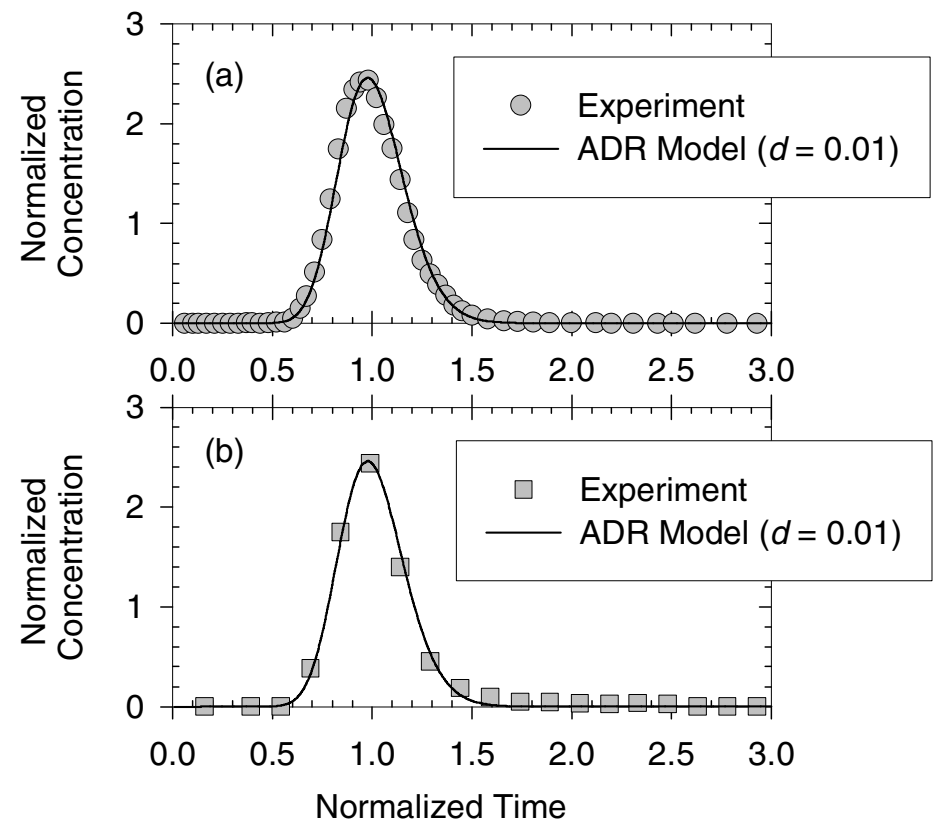

Figure S2. Comparison of experimental tracer test curves to those resulting from fitting the data with the axial dispersion reactor model: (a) bubble-diffuser column, (b) recirculation line. The agreement between experimental and fitted curves supported that each component of the bench-scale flowthrough reactor behaved similar to an ideal plug-flow reactor (PFR), and thus that the overall reactor could be modeled as a PFR-side PFR. 